\title{
EDITORIAL
}

\section{Continuity, Care, and Commitment: The Course of Patient-Clinician Relationships}

\author{
Moira Stewart, $\mathrm{PbD}$ \\ Department of Family Medicine, The University of Western Ontario, London, Ontario \\ Centre for Studies in Family Medicine, London, Ontario
}

Ann Fam Med 2004;2:388-390. DOI: 10.1370/afm.236.

$\mathrm{T}$ The day-to-day tasks of family medicine are accomplished through the interaction of patient and clinician during a visit, the "essential unit of medical practice." Coursing like a river underneath these discrete visits, however, is the ongoing relationship, manifesting dimensions more enduring than the qualities of any one visit, dimensions such as trust, caring, feeling, power, and purpose. Medical, nursing, and psychotherapeutic literature contains references to processes that have as a goal a strong patient-clinician relationship: a working alliance, ${ }^{2}$ a guarded alliance, ${ }^{3}$ or a therapeutic alliance. ${ }^{4}$

In my view, there are 4 central questions that researchers could focus on regarding the patient-clinician relationship: What is it? What aspects do patients expect and value? What can clinicians do or not do that will support the development of a positive and therapeutic relationship? What are the benefits of a positive relationship? Researchers have already covered some of this ground.

In qualitative studies, some of the processes of the patient-clinician relationship have been illuminated ${ }^{5,6}$ from the perspective of the patient, but not the clinician. In quantitative studies, findings to date have been summarized in several reviews that indicate modest effectiveness of the patient-clinician relation-

Conflicts of interest: none reported

\section{CORRESPONDING AUTHOR}

Moira Stewart, $\mathrm{PhD}$

Centre For Studies In Family Medicine

Thames Valley Family Practice Research Unit

Department of Family Medicine

100 Collip Circle, Suite 245, UWO Research Park

LONDON, Ontario

N6G 4X8

moira@uwo.ca ship in improving patient health outcomes..$^{7.9}$ For these studies, measures and interventions have been created, although most focus on one visit alone, and only a few are based on theory. More limiting is the tendency to focus only on communication skills to the neglect, in both teaching and research, of the more enduring dimensions of relationship listed above. As well, replication studies are still needed, especially those that (1) test feasible interventions, sustainable in the real world $i$ and (2) explicitly test the links among the variables in the hypothesized pathway: intervention $\rightarrow$ process outcomes $\rightarrow$ behavioral outcomes $\rightarrow$ patient health outcomes.

In this issue of the Annals, much to the authors' credit, all the articles on the patient-clinician relationship deal with enduring qualities of the ongoing relationship and not just one visit. Two articles focus on what patients value and perceive, ${ }^{10,11}$ and another 2 focus on the benefits of ongoing patient-clinician relationships. ${ }^{12,13}$ The latter 2 add to our understanding of the links or pathways that explain the influence of the patient-clinician relationship.

Mainous et al have conducted a fascinating reanalysis of the Direct Observation of Primary Care (DOPC) study of more than 4,000 patients to tease out the interrelationships among length of the patient-physician relationship, the shared experiences of patient and physician, and the value that patients place on continuity of care. The results emphasize the crucial importance of shared experiences (ie, "been through a lot together") to a positive attitude toward personal continuity of care. Statistically, the result is highly significant, but as well I salute the authors for showing the reader the scores for positive personal continuity. These scores show the rich interaction effect in which we see the impressive linear increase in positive attitude as the shared experiences increase for each level of the duration of relationship. At the 
same time, however, there is visible a small increase in the positive attitude in the group who had no shared experiences as the duration of the relationship rose to more than 4 years.

At the end of their article, Mainous et al pose a worthwhile question: what type of shared experiences have positive effects? I would like to take this opportunity to honor the memory of the late Dr. Ron McCord, professor in the Department of Family Medicine at East Tennessee State University, whose unpublished master's degree research asked and answered such a question. In a cross-sectional survey of patients' experiences and the quality of their current relationship with their family physician, McCord found that certain kinds of shared experiences were significantly associated with positive current patient-physician relationships: a complete physical examination, delivery of a child, care of children, personal problem, family problem, and serious illness. Not significantly associated were home visits, death in the family, pregnancy care, and serious illness in the family. The greater the number of shared experiences, the more positive the patient's rating of the relationship after controlling for demographic characteristics of the patient, frequency of visits, and seeing the regular doctor. ${ }^{14}$ Future research on the important topic of shared experiences should build on the work of Mainous et al and McCord.

Shers et al also deal with aspects of the relationship that patients value, but they present a different perspective on shared experiences. In this article we learn about patients' views of their future needs in serious circumstances (death of a family member, birth, discovery of cancer by a specialist) and less serious circumstances (minor foot operation, broken leg). The patients' purposes and motives for their expressed needs are illuminated by a qualitative component. Most patients desired physician-initiated emotional support indicating commitment and caring. A small subgroup expressed a need only for patient-initiated tangible support, such as prescribing and organizing. These data show the importance of the physician's commitment to the patient as a person, regardless of the setting of care, not only in the office but in the hospital and the home.

Saultz and Albedaiwi ${ }^{12}$ have conducted a rigorous systematic review of studies linking interpersonal continuity with patient satisfaction. In addition to the exceptional accompanying bibliography and the rigorous and clearly described methods, the article offers several hidden jewels. First, in a 2 -sentence justification for the choice of a generic outcome variable vs a diseasespecific outcome variable, they ask a central question for all researchers in our discipline: "If interpersonal continuity of care improves diabetes outcomes, does it necessarily follow that hypertension outcomes would also be improved?" Grumbach threw down the same gauntlet in the editorial for the first issue of the Annals of Family Medicine when he wrote, "the overall quality of generalist care is more than simply the sum of atomized, disease-specific measures." ${ }^{15}$ Although some researchers may not consider patient satisfaction to be the outcome measure of choice, family medicine researchers should value such generalist measures as patient satisfaction.

The second hidden jewel is a legitimate chickenor-egg discussion. Which comes first, continuity or satisfaction? Let us be clear about the design options to overcome such a dilemma: one is the randomized controlled trial with proof that the intended enhanced continuity was actualized; the other is a true inception cohort study of new patients receiving different types of care and observed over time. The latter, also called natural history studies, are much needed and vastly underutilized to answer some of the most important questions in family medicine research.

The findings, however, are the most stunning aspect of the article. Of the 22 studies reviewed, 19 showed significant positive associations between interpersonal continuity and patient satisfaction, 3 showed nonsignificant findings in the expected direction, and none showed trends in the opposite direction. Convincingly, not one of the studies reviewed showed any hint of the downside of continuity.

The article by Kerse et al makes a major contribution by associating patient-physician agreement on care with the important outcome of patient adherence with prescribed medication. This article adds to our thinking about mechanisms for the action of patient-physician relationship upon patient health outcomes. We can hypothesize that one testable pathway might be relationship $\rightarrow$ satisfaction $\rightarrow$ adherence $\rightarrow$ improved health. (An alternative mechanism might be the relationship directly influencing the patient's physiology, but that is not relevant to the present article.) Despite the logic of the hypothesized pathway, almost no previous intervention trials or cohort studies on the effect of patient-clinician relationships on patient health assess patient adherence as an intervening variable. ${ }^{7,16}$

It is surprising to read that continuity-of-care measures showed similar levels in New Zealand compared with the literature from the United States, except for the US Medicaid population, who experienced lower levels. In my view, researchers need to distinguish for policy makers when we are comparing among relatively high levels of continuity of care from when we are comparing low continuity with high continuity.

The articles in this issue provide some answers to 2 of the 4 central questions outlined earlier in this editorial: What aspects of the relationship do patients 
value, and what are the benefits of the relationship? As well, the articles overcome some of the limitations found in earlier literature. They focus on ongoing qualities of patient-clinician relationships; they assess some of the links in the pathway of the effects of patient-clinician relationships; they illuminate patient values and perceptions.

Much remains to be done. Future research needs to be more grounded in theories of relationships and to test a more holistic conceptual framework of influences on and influences of patient-clinician relationships. Future research needs to include the perspective of clinicians as well as patients.

We learn much from the articles in this issue. We learn that shared experiences are important to patients to whom they represent caring and commitment. We learn that the benefits of an ongoing patient-clinician relationship include patient satisfaction and patient adherence. Patient-clinician relationships are like rivers, requiring a continuous course in the form of continuity of care and deepening from the shared experience of shoals in the form of important patients life circumstances.

To read or post commentaries in response to this article, see it online at http://www.annfammed.org/cgi/content/full/2/5/388.

Key words: Physician-patient relations; continuity of patient care; primary health care; patient satisfaction

Submitted July 23, 2004; submitted, revised, August 5, 2004; accepted August 8, 2004.

\section{References}

1. Spence JC. The Purpose and Practice of Medicine: Selections from the Writings of Sir James Spence. London: Oxford University Press; 1960.
2. McWilliam CL, Brown JB, Stewart M. Breast cancer patients' experiences of patient-doctor communication: a working relationship. Patient Educ Couns. 2000;39:191-204.

3. Thorne CA. Guarded alliance: health care relationships in chronic illness. Image J Nurs Sch. 1989;21:153-157.

4. Bordin ES. The generalizability of the psychoanalytic concept of the working alliance. Psychotherapy. 1979;16:252-260.

5. Seifert M. How do people get well? Paper presented at: Annual Meeting of the North American Primary Care Research Group; May 1987; Minneapolis, Minn

6. McWilliam CL, Stewart M, Brown JB, et al. Creating empowering meaning: an interactive process of promoting health with chronically ill older Canadians. Health Promot Int. 1997;12:1-13.

7. Stewart M. Effective physician-patient communication and health outcomes: a review. Can Med Assoc J. 1995;152:1423-1433.

8. Di Blasi A, Harkness E, Ernst E, Georgiou A, Kleijnen J. Influence of context effects on health outcomes: a systematic review. Lancet. 2001;357:757-762

9. Griffin S, Kinmonth AL, Veltman M, Gillard S, Grant J, Stewart M. A systematic review of interventions to alter the interaction between patients and practitioners. Ann Fam Med. In press.

10. Mainous AG III, Goodwin MA, Stange KC. Patient-physician shared experiences and value patients place on continuity of care. Ann Fam Med. 2004;2:452-454.

11. Schers $H$, van de Ven $C$, van den Hoogen $H$, Grol $R$, van den Bosch W. Patients' needs for contact with their GP at the time of hospital admission and other life events. A quantitative and qualitative exploration. Ann Fam Med. 2004;2:462-468.

12. Saultz J, Albedaiwi W. Interpersonal continuity of care and patient satisfaction: a critical review. Ann Fam Med. 2004;2:445-451.

13. Kerse N, Buetow S, Mainous AG III, Young G, Coster G, Arroll B. The doctor-patient relationship and compliance with medication: a primary care investigation. Ann Fam Med. 2004;2:455-461.

14. McCord R. The Doctor-Patient Relationship and Experiences Shared by the Doctor With the Patient. [MCISc Research Paper]. Department of Family Medicine, The University of Western Ontario, 1990.

15. Grumbach K. Chronic illness, comorbidities, and the need for medical generalism. Ann Fam Med. 2003;1:4-7

16. Stewart M, Brown JB, Donner A, et al. The impact of patient-centered care on outcomes. J Fam Pract. 2000;49:796-804. 